\title{
Graves's Disease, an Unusual Complication: Raised Intracranial Pressure Due to Premature Fusion of Skull Sutures
}

\author{
D. C. ROBINSON, R. HALL, and D. S. MUNRO \\ From the Departments of Child Health and Medicine, Royal Victoria Infirmary, Newcastle upon Tyne; \\ and The Department of Pharmacology and Therapeutics, Royal Infirmary, Sheffield
}

Graves's disease is uncommon in childhood, only $5 \%$ of the total cases falling within the agegroup 0-15 years (Saxena, Crawford, and Talbot, 1964). Excluding the transient neonatal form of thyrotoxicosis, we have been able to trace only 4 cases of hyperthyroidism beginning before 2 years. The purpose of this paper is to describe a boy with Graves's disease who presented in the second year of life, and subsequently developed raised intracranial pressure from premature fusion of his skull sutures.

\section{Case Report}

A 20-month-old boy was referred to Dr. W. D. Elliott because of diarrhoea and failure to thrive. From 15 months he had had bouts of diarrhoea lasting 2 or 3 weeks during which he passed up to 6 unformed green stools daily followed by normal stools for a week or two. For about the same period he had failed to gain weight and during the month before he was seen he had lost $0.45 \mathrm{~kg}$. (1 lb.). He was admitted to hospital for investigation.

He was an intelligent, nervous boy. His milestones had been normal, he sat at 5 months, said odd words at 6 months, and walked at 10 months. Psychological tests revealed a Merrill-Palmer Intelligence Scale IQ of 107 and a Vineland Social Maturity Quotient of 118. Psychological assessment showed his intellectual level to be near the top of the normal range of cognitive ability (90-110) and his social development was also high (110-119). His weight was just below the 10th centile and his height just above the 25 th centile (Fig. 1a and $b$ ). There was a firm enlargement of the thyroid, with a loud bruit. The goitre was easily visible with the head slightly extended (Fig. 2). His hair was sparse. His pulse rate varied between 110 and 160/ min. and did not fall below $100 / \mathrm{min}$.; the blood pressure was $140 / 60 \mathrm{~mm}$. Hg. Though several observers noted his 'stare', there was no exophthalmos or lid

Received September 10, 1968. retraction. The optic fundi were normal and the head circumference was $47.5 \mathrm{~cm}$. which is on the 10th centile for his age. The skull shape was normal but $x$-ray (at 20 months) showed fusion of all skull sutures.

While in hospital he had intermittent pyrexia up to $39.4{ }^{\circ} \mathrm{C}$. (Fig. 3). When febrile he sweated profusely but he did not seem ill. He slept soundly at night but always threw off his bed-clothes. During the day he was strikingly hyperactive and would never sit still.

On further questioning the parents revealed that there had been a personality change at about the time that the diarrhoea began. Previously a happy, equable child, he had become nervous, easily excited and frightened, and prone to temper tantrums. He was born at 37 weeks' gestation by elective caesarean section. The pregnancy had been normal except for maternal iron deficiency anaemia. His birthweight was $3175 \mathrm{~g}$. and the neonatal period had been normal. His weight gain (as recorded by the Welfare Clinic he attended) had been entirely satisfactory, consistently just below the 50th centile. At $9 \frac{1}{2}$ months his rate of weight gain decreased and this trend was not reversed till treatment was started.

There was no family history of thyrotoxicosis, goitre, or exophthalmos, and no clinical thyroid disease could be detected in his parents or sibs.

\section{Investigations}

Thyroid investigations. Investigations confirmed that he was severely thyrotoxic. The serum $\mathrm{PB}^{127} \mathbf{I}$ was $16.4 \mu \mathrm{g} . / 100 \mathrm{ml}$. The thyroid ${ }^{1: 1} \mathrm{I}$ uptake at 6 hours was $83 \%$ of the dose, and after tri-iodothyronine $100 \mu \mathrm{g}$. daily for one week was $86 \%$ of the dose. The results of detailed iodine studies are shown in the Table. Simultaneous readings of thyroid ${ }^{131} \mathrm{I}$ uptake and plasma ${ }^{131}$ I uptake were taken at arbitrary times determined by when he passed urine, at 2 hours 40 minutes and 4 hours 14 minutes after ingestion of the ${ }^{131} \mathrm{I}$. The average blood radioactivity over this period was then calculated from the formula: 

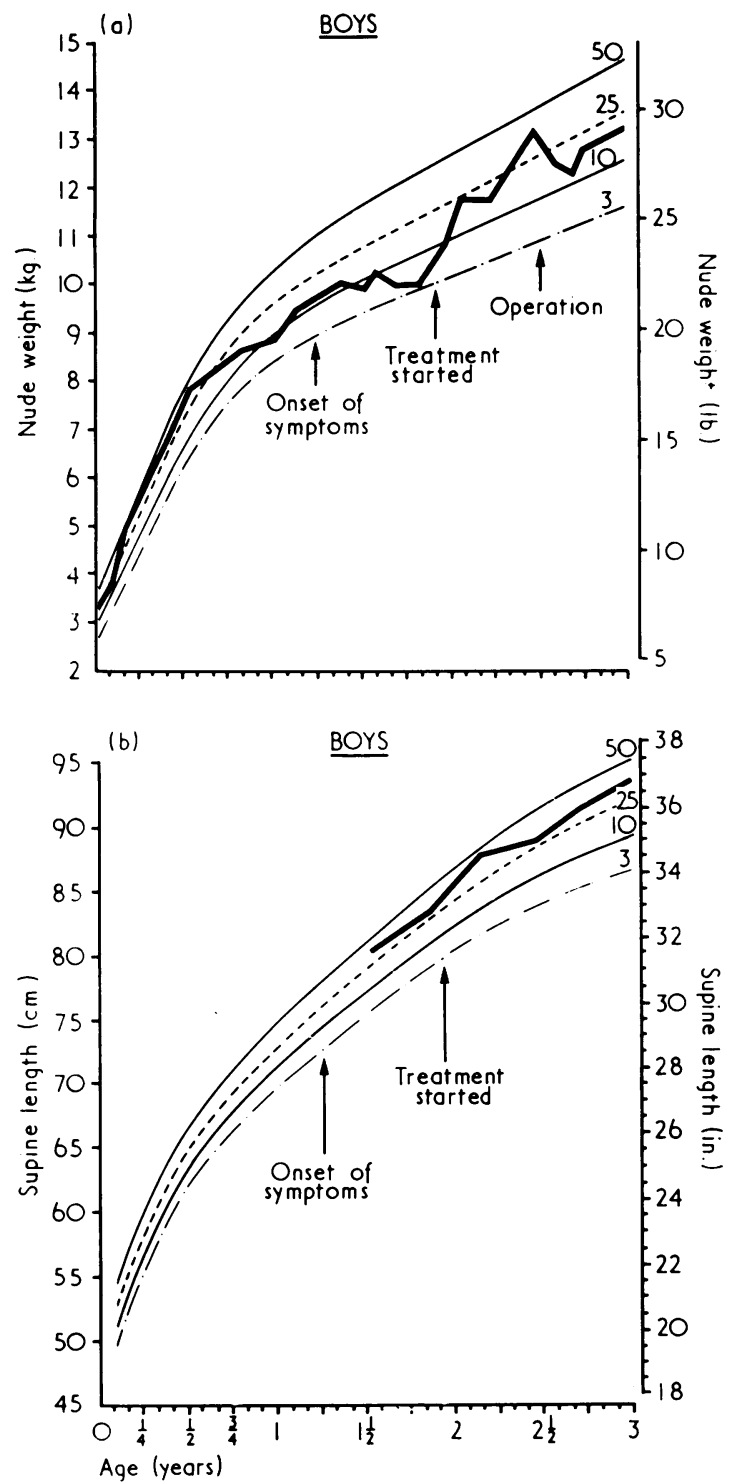

FIG. 1.-Weight and height charts of the patient.

$$
\begin{gathered}
B=\frac{B_{1}-B_{2}}{\log _{e} B_{1}-\log _{e} B_{2}} \\
=\frac{B_{1}-B_{2}}{2 \cdot 3\left(\log _{10} B_{1}-\log _{10} B_{2}\right)}
\end{gathered}
$$

Where $\mathbf{B}=$ average plasma ${ }^{131} \mathrm{I}$ concentration, and $B_{1}=$ plasma ${ }^{131} I$ concentration at $2 \mathrm{hr}$. $40 \mathrm{~min}$. after dose; $B_{2}=$ plasma ${ }^{131} \mathrm{I}$ concentration at $4 \mathrm{hr}$. $14 \mathrm{~min}$. after dose.

The thyroid and renal iodide clearances were then derived (Alexander et al., 1962). The thyroid iodide

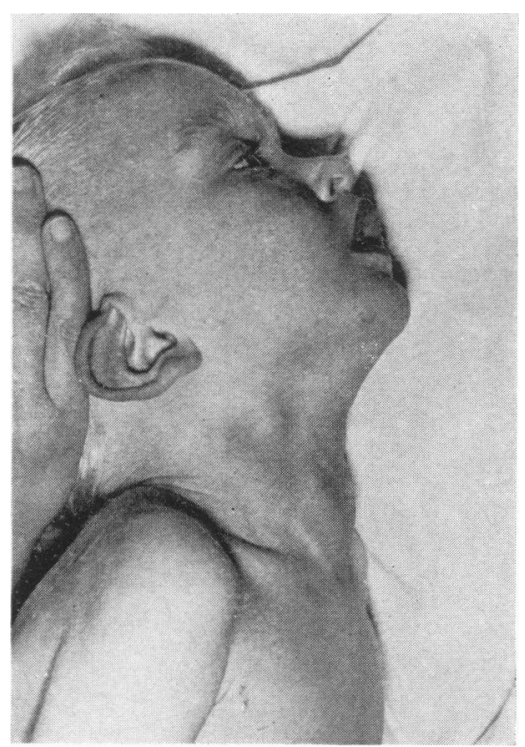

Fig. 2.-Thyroid enlargement.

clearance was $87 \mathrm{ml} . / \mathrm{min}$. (normal adult range $6 \cdot 6-44 \cdot 4$, mean $22 \cdot 7 \pm 1 \cdot 7$ standard error), renal iodide clearance was $10.5 \mathrm{ml} . / \mathrm{min}$. (normal adult range $11 \cdot 7-61 \cdot 8$, mean $30.5 \pm 2.0$ standard error). The plasma was passed through a column containing the resin IRA 400 (Cl) which removed iodide. An estimate of the inorganic radio-iodide level was obtained by subtracting the effluent count from the initial count. These results are shown in the Table and Fig. 4. The plasma $\mathrm{PB}^{131} \mathrm{I}$ at 24 and 48 hours was extracted with butanol (DeGroot and Stanbury, 1959) which removed $95 \%$ of the radioactivity, a normal result.

Thyroglobulin antibodies were positive in a titre of $1 / 15,625$. A high level of long-acting thyroid stimulator (LATS) was present in the serum, there being approximately 10 milli-units of the standard per $\mathrm{ml}$.

TABLE

Thyroid Investigation Results

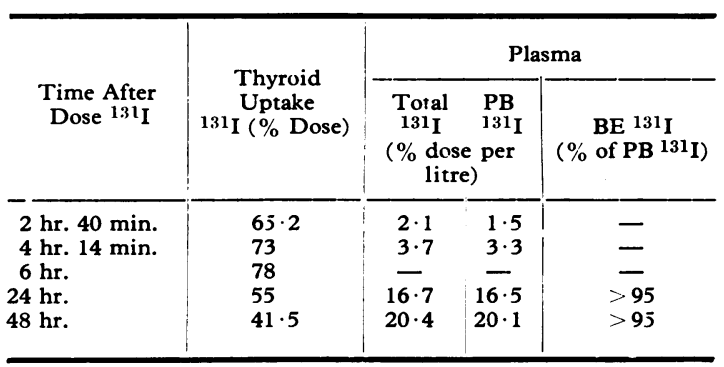




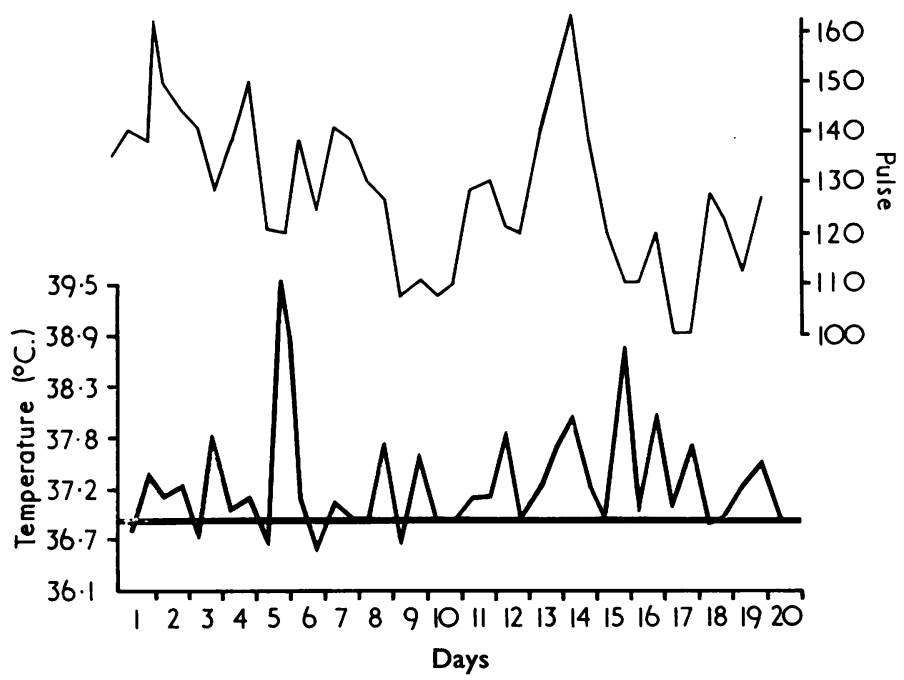

FIG. 3.-Pulse and temperature charts of the patient.

Other investigations. $\mathrm{Hb} 72 \%, \mathrm{PCV} 34 \%$, and MCHC $31.5 \%$, white cells $7500 /$ cu.mm.; differential count normal; serum iron $62 \mu \mathrm{g} . / 100 \mathrm{ml}$., serum cholesterol $86 \mathrm{mg}$. $/ 100 \mathrm{ml}$., plasma protein $5.6 \mathrm{~g} . / 100 \mathrm{ml}$., serum calcium $10.7 \mathrm{mg} . / 100 \mathrm{ml}$., phosphate $4.6 \mathrm{mg}$. P $1100 \mathrm{ml}$., serum alkaline phosphatase $18 \mathrm{KA}$ units. ECG showed only sinus tachycardia at $145 / \mathrm{min}$.; urine amino acid chromatography showed an aminoaciduria of generalized distribution; EEG was normal.

Radiological studies at 21 months showed a normal chest film, and much advanced bone age (Fig. 5) estimated at the hand and wrist at $5 \frac{1}{2}-6$ years (Greulich and Pyle, 1959). Skull $x$-ray showed virtually total premature fusion of the sagittal, coronal, and lambdoid sutures (Fig. 6). His dental age was estimated by radiological examination as being between 24 and 30 months (chronological age 20 months).

\section{Progress}

Treatment was started at 23 months with carbimazole $30 \mathrm{mg}$. daily in divided doses. 8 weeks later he had

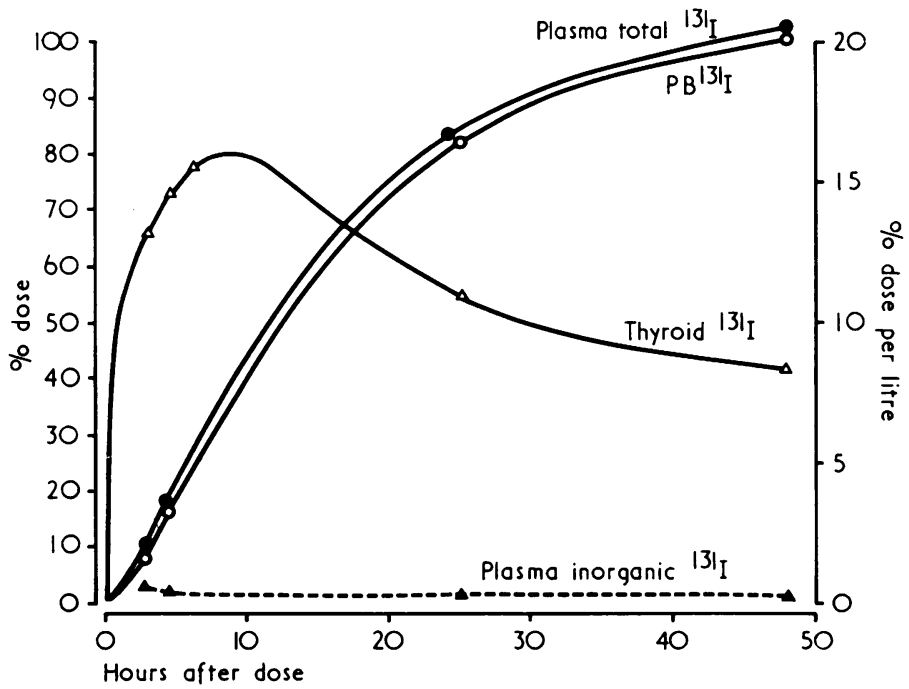

FIG. 4. -Thyroid ${ }^{131}$ I uptake and plasma total ${ }^{131}$ I, inorganic ${ }^{131} I$ and protein-bound ${ }^{131} I$ after a tracer dose of ${ }^{131}$ I. 
become clearly hypothyroid: he was sleepy, constipated, and complained of feeling cold. At that time he was conspicuously inactive, his extremities were cold, and his face was slightly puffy. He had gained $900 \mathrm{~g}$. in weight since treatment was started, and the goitre had become larger (maximum neck circumference had increased from 48 to $50 \mathrm{~cm}$.). The dose of carbimazole was halved and 1-thyroxine in a dose of $0.2 \mathrm{mg}$. daily was introduced. A month later he was clinically euthyroid and the goitre had become slightly smaller.

At the age of 29 months having then had 6 months' treatment, his mother reported that he had had 3 episodes of vomiting with headache, each attack lasting for several days. The first of these episodes had occurred 8 weeks previously. He was found to have bilateral papilloedema. The fundi had been examined 3 months before when the optic discs were normal. During the 8 months that he had been under observation his head circumference had increased from 47.5 to $48 \mathrm{~cm}$., but this small increase is within the observer error.

An air ventriculogram showed normal lateral and third ventricles. It was concluded that the papilloedema was due to raised intracranial pressure resulting from continued brain growth in the presence of premature fusion of the skull sutures. Linear craniectomies were therefore performed by $\mathrm{Mr}$. L. Lassman. At operation the brain was found to be 'tight' and the sutures were completely closed. Linear craniectomies were made (in two stages with a 10-day interval) to open up the coronal, lambdoid, and sagittal sutures. Polyethylene strips were applied over the edges of the linear craniectomies and secured with clips.

His post-operative course was uncomplicated. 10 days after the second stage of the operation the optic discs were less swollen, and a month later they were completely normal. There have been no further episodes of headache and vomiting. 24 months after the beginning of treatment on the same dose of carbimazole and 1-thyroxine he remains clinically euthyroid, and his weight gain and growth in height are normal.

Family Studies. No LATS was detectable in the unconcentrated sera of the parents or of the two sibs. Thyroglobulin antibodies were also demonstrated in the sera of his mother aged 36 years (titre 1/125) and his sister aged 8 years (titre $1 / 20$ ) but not of his father (aged 34 years) or his brother (aged 7 years). His mother's serum also showed gastric parietal cell antibodies detected by the immunofluorescence technique. Complement-fixation tests for thyroid and gastric antibodies were negative in the whole family as were gastric intrinsic factor antibodies and antinuclear factor.

\section{Discussion}

Apart from transient neonatal thyrotoxicosis in infants born to mothers with Graves's disease (Rosenberg, Grand, and Silbert, 1963), thyrotoxicosis beginning before the third year of life is extremely rare. Hayles (1966), in a review of all

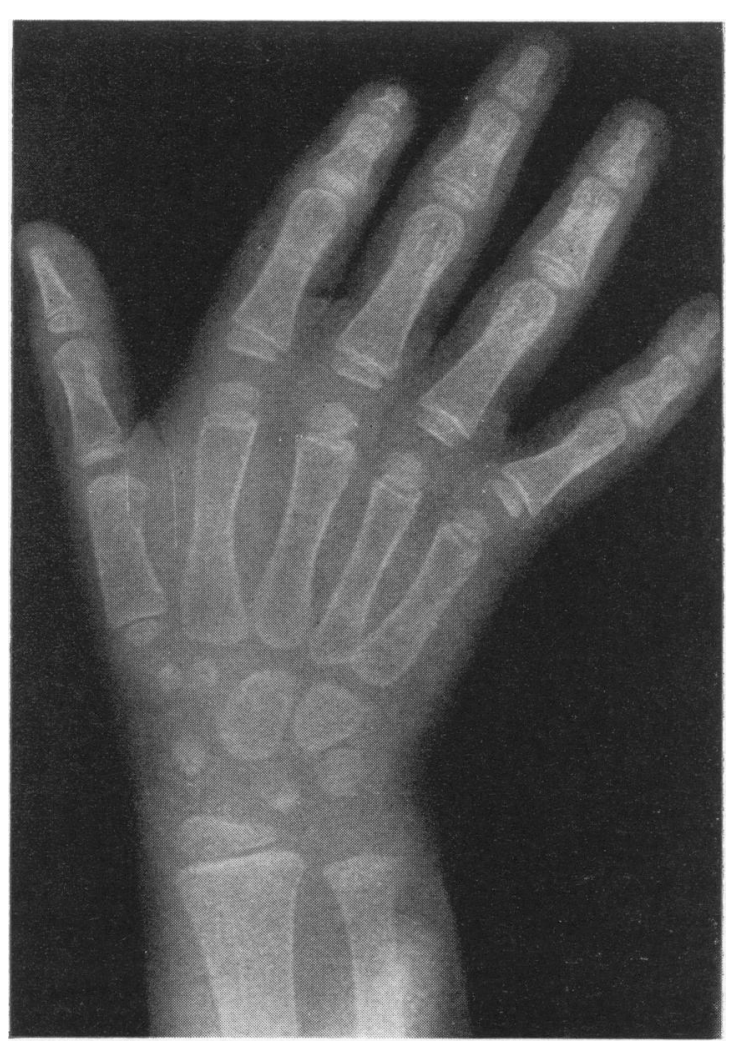

FIG. 5.-X-ray of hand and wrist showing advanced bone age ( $5 \frac{1}{2}-6$ years).

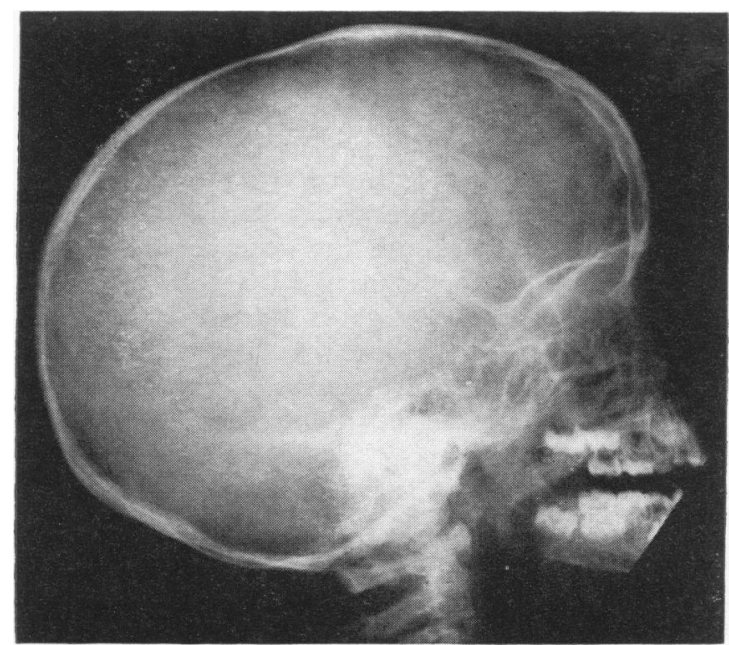

FIG. 6.-Skull x-ray at 20 months, showing virtually total premature fusion of the sagittal, coronal, and lambdoid sutures. 
the cases of childhood thyrotoxicosis at the Mayo Clinic over a 40-year period, refers to one child whose symptoms started at 11 months, but no details are given about the subsequent progress. This is presumably the same child described by Helmholtz (1926) in whom hyperthyroidism was diagnosed at the age of 3 years and cured by partial thyroidectomy. At 11 months she developed diarrhoea followed by exophthalmos, tachycardia, thyroid enlargement, and loss of weight leading to emaciation. Braid and Neale (1930) described a girl with thyrotoxicosis whose symptoms first appeared after pneumonia at the age of 1 year. At the age of $2 \frac{1}{2}$ years after measles she became much worse. A right thyroid lobectomy was performed but she died immediately after the operation. The thyroid was uniformly enlarged and both the operation specimen and the remaining thyroid at necropsy showed diffuse hyperplasia. Elliott (1935) described a girl with exophthalmic goitre whose symptoms began when she was 6 months old. She had recurrent thyroid crises which were not adequately controlled by iodine, but after subtotal thyroidectomy at the age of 2, she became mildly hypothyroid. Finally Paterson and Gallant (1931) described a girl who had exophthalmos at the age of 4 months. At the age of 8 years exophthalmos was still present and there was clinical evidence of hyperthyroidism, which persisted at least until she was 14 (Ellis, 1935). We have found no other reports in the literature (excluding transient neonatal thyrotoxicosis) of hyperthyroidism beginning before the age of 2 years.

Detailed thyroid investigations confirmed the presence of hyperthyroidism. Labelled thyroid hormone entered the circulation at the earliest time studied ( 2 hours 40 minutes after the tracer dose) and by 24 and 48 hours the plasma PB $^{131}$ I had reached the extremely high levels of $16.5 \%$ and $20 \cdot 1 \%$ respectively of the dose per litre. In thyrotoxic adults the highest $\mathrm{PB}^{131} \mathrm{I}$ level at 48 hours reported in a large series by Goodwin et al. (1951) was $3.4 \%$ of the dose per litre. The much higher value seen in our case could have been due to a very low intrathyroidal iodine pool, to discharge of labelled thyroid hormone into a small plasma volume, or to reduced hepatic uptake of thyroid hormone. It is not possible to decide which combination of factors was responsible in this case. Since more than $95 \%$ of the PB $^{131}$ I at 24 and 48 hours was extractable by butanol, the raised $\mathrm{PB}^{131}$ I was not due to the iodinated albuminlike compound found in the plasma of some thyrotoxic patients (Stanbury and Janssen, 1962).
The high level of $\mathrm{PB}^{131} \mathrm{I}$ is also of interest because of the recent description of a positive correlation between the circulating levels of PB ${ }^{131}$ I and LATS (Carneiro, Dorrington, and Munro, 1966). In our case both PB ${ }^{131}$ I and LATS levels were high. The high concentration of LATS confirmed that the hyperthyroidism occurred as part of the syndrome of Graves's disease. The familial association of thyroid disease and thyroid autoimmunity has often been described (Hall, Owen, and Smart, 1960), and is particularly well marked in the families of children with auto-immune thyroid disease (Hall, Saxena, and Owen, 1962). The low titres of thyroglobulin antibodies found in the patient's mother and sister imply the presence of mild subclinical auto-immune thyroid disease.

Though the age of onset of symptoms in the boy described here was exceptionally young (15 months), his symptoms were at first characteristic of childhood thyrotoxicosis, with the usual combination of nervousness, hyperkinesis, sweating, and loss of weight in spite of increased appetite. His weight for the first 7 months of life was just below the 50th centile, but at $9 \frac{1}{2}$ months he was gaining less rapidly (Fig. 1). This may represent the beginning of the illness, though symptoms were not noticed until several months later. The increased rate of weight gain at the beginning of treatment is clearly shown, but his height has remained at about the 25 th centile after 24 months' treatment.

One of the curious and variable features of childhood thyrotoxicosis is its effect on growth. Some children with this disorder show an acceleration of growth in height. Holmgren (1909) found that about $80 \%$ of cases under the age of 20 were above average height for their age, the acceleration of growth corresponding to the time of onset of symptoms. Similarly, Reilly (1940) found acceleration of clinical growth in 36 out of 44 children with Graves's disease, and Hung, Wilkins, and Blizzard, (1962) made the same observation in 11 out of 14 children. Greene and Singer (1965) reported greatly increased linear growth between the ages of 13 and 15 in a boy with thyrotoxicosis and Klinefelter's syndrome.

Though in the case reported here there was no acceleration of growth in height, when he was first seen at 20 months his bone age was greatly advanced to about 6 years. There was therefore a striking disparity between his growth in height which was below average and his greatly advanced bone age. Hung et al. (1962) have commented on this disparity in a few of their patients; out of 14 children with thyrotoxicosis 8 had an advanced bone age 
and height age, 3 had an advanced bone age only, and $3 \mathrm{had}$ an advanced height age only. That is to say in childhood thyrotoxicosis, height age and bone age may or may not be advanced and they appear to behave independently.

There is no information in the literature about skull size in childhood thyrotoxicosis. This boy's head circumference was slightly below average for his age, as was his height. It is suggested that the combination of the very early onset of the disease and the greatly advanced bone age, without any corresponding increase in the rate of growth of skull size, accounts for the unique features of this case, namely the premature fusion of the sutures of the skull, the subsequent development of raised intracranial pressure with papilloedema, presumably due to continuing brain growth within a skull unable to expand, and the relief of that pressure by linear craniectomies.

\section{Summary}

A boy aged 20 months presented with thyrotoxicosis. The onset of the disease may have been as early as 10 months. At 29 months, after 6 months' treatment for thyrotoxicosis, he developed raised intracranial pressure due to premature fusion of skull sutures. This was relieved by linear craniectomies.

\section{REFERENCES}

Alexander, W. D., Koutras, D. A., Crooks, J., Buchanan, W. W.' Macdonald, E. M., Richmond, M. H., and Wayne, E. J. (1962). Quantitative studies of iodine metabolism in thyroid disease. Quart. F. Med., 31, 281.

Braid, F., and Neale, A. V. (1930). A case of exophthalmic goitre. Arch. Dis. Childh., 5, 229.
Carneiro, L., Dorrington, K. J., and Munro, D. S. (1966). Relation between long-acting thyroid stimulator and thyroid function in thyrotoxicosis. Lancet, 2, 878.

DeGroot, L. J., and Stanbury, J. B. (1959). The syndrome of congenital goiter with butanol-insoluble serum iodine. Amer. F. Med., 27, 586 .

Elliott, P. C. (1935). Exophthalmic goiter before one year of age. J. Pediat., 6, 204.

Ellis, R. W. B. (1935). Hyperthyroidism dating from infancy. Proc. roy. Soc. Med., 23, 832.

Goodwin, J. F., Macgregor, A. G., Miller, H.; and Wayne, E. J. (1951). The use of radioactive iodine in the assessment of thyroid function. Quart. F. Med., 20, 353.

Greene, R., and Singer, W. (1965). Thyrotoxicosis and gigantism associated with 'Klinefelter's syndrome'. Brit. med.f., 2, 1523.

Greulich, W. W., and Pyle, S. I. (1959). Radiographic Atlas of Skeletal Development of the Hand and Wrist, 2nd ed. Stanford University Press, Stanford, California; Oxford University Press, London.

Hall, R., Owen, S. G., and Smart, G. A. (1960). Evidence for genetic predisposition to formation of thyroid autoantibodies. Lancet, 2, 187.

- Saxena, K. M., and Owen, S. G. (1962). A study of the parents of patients with Hashimoto's disease. ibid., 2, 1291.

Hayles, A. B. (1966). Exophthalmic goiter. In. Brennemann's Practice of Pediatrics, Vol. I, Chapter 49, p. 28. Ed. by V. C. Kelley. W. F. Prior, Hagerstown, Maryland.

Helmholtz, M. F. (1926). Exophthalmic goiter in childhood. F. Amer. med. Ass., 87, 157.

Holmgren, I. (1909). Ueber den Einfluss der Basedowschen Krankheit und verwandter Züstande auf das Längenwachstum nebst einigen Gesetzen der Ossifikation. Nord. med. Ark. II. Inre Med., 42, 1.

Hung, W., Wilkins, L., and Blizzard, R. (1962). Medical therapy of thyrotoxicosis in children. Pediatrics, 30, 17.

Paterson, D., and Gallant, W. (1931). Hyperthyroidism. Proc. roy. Soc. Med., 24, 569.

Reilly, W. A. (1940). Thyrotoxicosis. Amer. F. Dis. Child., 60, 79.

Rosenberg, D., Grand, M. J. H., and Silbert, D. (1963). Neonatal hyperthyroidism. New Engl. F. Med., 268, 292.

Saxena, K. M., Crawford, J. D., and Talbot, N. B. (1964). Childhood thyrotoxicosis: A long term perspective. Brit. med. F., 2, 1153 .

Stanbury, J. B., and Janssen, M. A. (1962). The iodinated albuminlike component of the plasma of thyrotoxic patients. $\mathcal{F}$. clin. Endocr., 22, 978.

Correspondence to Dr. R. Hall, Ward 10 Office, Royal Victoria Infirmary, Newcastle upon Tyne.

\section{Donald Paterson Prize Essay}

A prize essay competition will be held, open to medical practitioners registered in the United Kingdom for not more than 10 years. The value of the prize will be 25 pounds.

The subject of the essay shall be related to paediatrics but will be chosen individually by candidates. The essay shall consist substantially of unpublished work.

Entry forms and further information may be obtained from the Honorary Secretary, British Paediatric Association, Institute of Child Health, 30 Guilford St., London W.C.1. The closing date for entries will be June 30, 1969. 